\title{
고조파제어 $(\mathrm{HHC})$ 기법을 이용한 저속 하강 비행중인 로터의 진동하중 억제에 관한 연구
}

유영현, 정성남*

\section{Vibratory Loads Reduction of a Rotor in Slow Descent using Higher Harmonic Control Technology}

\author{
Younghyun You and Sung Nam Jung* \\ Department of Aerospace Information Engineering, Konkuk University
}

\begin{abstract}
In this paper, a higher harmonic control $(\mathrm{HHC})$ methodology is applied to find the optimum input scenario for the vibratory hub loads reduction. A comprehensive aeroelastic analysis code, CAMRAD II, is used to model the HART (Higher-harmonic-control Aeroacoustic Rotor Test) II rotor, and parametric study is conducted for the best $\mathrm{HHC}$ inputs leading to a minimum vibration (MV) condition. The resulting outcomes are compared with the earlier HART II test results. It is indicated that the control input adopted in the MV condition showed less satisfactory results. The new MV condition obtained in the present investigation can achieve $45 \%$ lower vibration level than the baseline uncontrolled condition. The optimum HHC input results lead to 3/rev harmonic input having $0.8^{\circ}$ amplitude and $350^{\circ}$ phase angle. About $5 \%$ reduction in the required power is possible but accompanies with the increase of vibration level.
\end{abstract}

\section{초 록}

본 연구에서는 능동적인 블레이드 제어기법인 고조파제어(Higher Harmonic Control, $\mathrm{HHC}$ ) 기법을 적용하여 로터의 허브 진동하중을 억제하기 위한 최적 제어입력을 탐색하였 다. 통합 공탄성 해석 프로그램인 CAMRAD II를 이용하여 HART II 로터를 모델링하고 다 양한 $\mathrm{HHC}$ 입력 조건에 대하여 파라미터 연구를 수행하여 최대의 진동하중을 감소시키기 위한 제어입력을 찾고, HART II 시험에서 정한 최소 진동 조건에서의 허브 진동하중과 비 교하였다. 파라미터 연구를 통하여 HART II 시험에서의 최소 진동 조건에서는 진동하중이 증가하는 것을 확인하였다. 허브 진동하중을 감소시키기 위한 최적의 제어입력은 $3 / \mathrm{rev}$ 의 가진주파수에서 찾을 수 있었고 0.8 도의 진폭과 350 도의 위상각을 갖는 제어입력을 이용하 는 경우에 기준조건대비 약 $45 \%$ 의 허브 진동하중 감소효과를 얻었다. $\mathrm{HHC}$ 기법을 이용 하는 경우의 로터의 파워 감소는 $5 \%$ 미만으로 나타나고, 성능이 향상되는 경우에는 대부 분 진동이 증가하는 경향을 보였다.

Key Words : Higher Harmonic Control(고조파제어기법), HART II, Hub Vibratory Loads(허브 진동하중), Vibration Index(진동 지표), Minimum Vibration (최소 진동)

† Received: April 1, 2013 Accepted: May 22, 2013

* Corresponding author, E-mail : snjung@konkuk.ac.kr http://journal.ksas.or.kr/

pISSN 1225-1348 / eISSN 2287-6871 


\section{I. 서 론}

회전익기는 고정익기와 다르게 메인 로터 시 스템에서 양력과 추력을 발생시킴과 동시에 대부 분의 비행제어 능력을 담당한다. 이러한 회전익 기 로터의 특수성은 메인 로터 주위의 비정상 공 력 환경의 원인이 되고, 메인 로터에 작용하는 비정상 공기력은 동체 진동의 원인으로 작용한 다. 회전익기에서 발생하는 진동은 회전익기의 유지, 보수비용과 승무원 및 승객의 편의성 등과 직접적으로 연관되어 있기 때문에 이러한 진동을 억제하기 위한 노력이 오랜 시간 지속되어 왔다.

회전익기의 진동을 억제하기 위한 방법은 수 동적인 방법과 능동적인 방법으로 나누어진다. 수동적인 진동 제어기법에는 진자운동기 (pendulum absorber)[1]와 모드조절법(modal placement methods)[2] 등이 있는데, 이러한 수 동적인 제어기법은 비교적 간단한 장치를 이용하 여 원하는 진동을 억제할 수 있는 장점이 있다. 하지만 제한적인 운용조건에서 추가적인 중량 증 가의 요인이 있고 항력이 커지는 등의 단점이 있 다. 능동적인 제어기법에는 ACSR(Active Control of Structural Response) 기법과, $\mathrm{HHC}$ (Higher Harmonic Control) 기법, IBC(Individual Blade Control) 기법, ATF(Active Trailing Edge Flap) 기법, 그리고 ATR(Active Twist Rotor) 기법 등 이 있다[3 7]. 능동적인 제어기법은 회전익에 직 접 작용하여 비정상 공기력을 제어함으로 진동의 원인을 억제하는 방법이다. 이 방법은 폭넓은 주 파수 범위에서 작동이 가능하여 진동 억제 성능 을 보다 많이 기대할 수 있는 특징이 있다.

능동적인 제어기법 중에서 $\mathrm{HHC}$ 기법은 비회 전 스와시판(swashplate)에 작동기를 설치하여 로터 블레이드의 피치각을 조절하여 블레이드의 공기력을 제어함으로써 진동을 줄이는 기법이다. $\mathrm{HHC}$ 기법에 대한 연구는 1950년대 후반부터 시 작되어져 왔으며 현재까지도 활발한 연구가 수행 되고 있다[8,9]. 연구 초기에는 $\mathrm{HHC}$ 기법을 이용 한 진동억제에 대한 연구에 관심이 집중되었고, 최근에는 소음 억제에 대한 연구도 활발하게 진 행되고 있다. 특히 HHC 기법을 이용한 BVI (Blade-Vortex Interaction) 소음 억제 기법에 대 한 이해와 연구를 위해 1994년에는 국제공동연구 인 HART I 프로그램이 수행되었고, 2001년도에 는 후속 프로그램인 HART II 시험이 수행되었 다[10, 11]. 이 시험을 통하여 로터 블레이드에 작용하는 공력하중, 구조하중, 블레이드 공탄성 응답 등과 함께 소음과 진동을 측정하여 $\mathrm{HHC}$
Table 1. Comparison of $\mathrm{HHC}$ inputs of HART I/II for minimum vibration

\begin{tabular}{|c|c|c|}
\hline Values (unit) & HART I [8] & HART II [9] \\
\hline Frequency (/rev) & 3 & 3 \\
Amplitude $\left({ }^{\circ}\right)$ & 0.83 & 0.79 \\
Phase angle $\left(^{\circ}\right)$ & 178 & 180 \\
\hline
\end{tabular}

제어입력이 소음과 진동에 미치는 영향을 고찰하 였다.

HART II 시험은 다양한 비행 조건에 대하여 풍동시험이 수행 되었는데 대표적인 조건은 외부 제어 입력이 없는 기본(BL) 조건과 $\mathrm{HHC}$ 기법을 적용한 최소 소음 $(\mathrm{MN})$ 과 최소 진동 $(\mathrm{MV})$ 조건이 다. HART II 시험에서 사용된 $\mathrm{MN}$ 와 $\mathrm{MV}$ 조건 은 Table 1 에서 보는 바와 같이 철저한 검증 과 정 없이 HART I 시험에서의 $\mathrm{MN}$ 와 $\mathrm{MV}$ 조건의 $\mathrm{HHC}$ 입력과 유사한 제어입력을 사용하였다. 따 라서 HART II 시험에서의 $\mathrm{MN}$ 와 $\mathrm{MV}$ 조건이 실 제로 소음과 진동을 최소화 시킬 수 있는 $\mathrm{HHC}$ 입력인지는 알 수 없는 실정이다.

본 연구에서는 HART II 시험에서 이용한 MV 조건에서의 진동하중이 실제 최소 진동하중을 나 타내는지 평가하고, 실제 최소 진동하중을 나타 내는 제어입력을 찾기 위한 파라미터 연구를 수 행하였다. 또한 로터의 성능과 허브 진동하중을 함께 분석하여 로터의 성능을 개선시키면서 동시 에 진동을 억제시키는 최적의 $\mathrm{HHC}$ 조건을 찾고 자하였다. 해석은 통합 공탄성 해석 프로그램인 CAMRAD II[12]를 이용하였다.

\section{II. 본 론}

\section{1 공탄성 해석 검증}

공탄성 해석 코드의 검증을 위해 CAMRAD II를 이용하여 HART II 로터를 모델링하고 내장 된 공력모듈을 이용하여 공탄성 해석을 수행하였 다. 해석결과는 실험값과 비교하여 해석 코드의 정확성을 검증하였다. 해석에 사용된 HART II 로터는 BO-105 무힌지 로터의 $40 \%$ Mach scaled 축소 로터이다. 로터 블레이드는 16 개의 유한요 소로 모델링하였고 각각의 유한요소는 9 개의 자 유도를 갖는다. 공력하중을 계산하기 위해 다중 후류 모델(Multiple-trailer wake model)을 이용 하였으며 본 논문에서는 13 개의 후류를 사용하였 다. 비행조건은 전진비 0.15 의 저속으로 6.5 도 하 강 비행하는 조건이며, 이때 로터의 회전축은 5.3 
Table 2. General properties of HART II rotor blades

\begin{tabular}{|c|c|}
\hline Properties, unit & Values \\
\hline Airfoil & NACA23012mod \\
Radius, m & 2 \\
Chord, m & 0.121 \\
Linear twist, deg & -8 \\
Solidity $(\sigma)$ & 0.077 \\
Thrust coefficient & 0.0044 \\
Rotor speed, rpm & 1041 \\
\hline
\end{tabular}

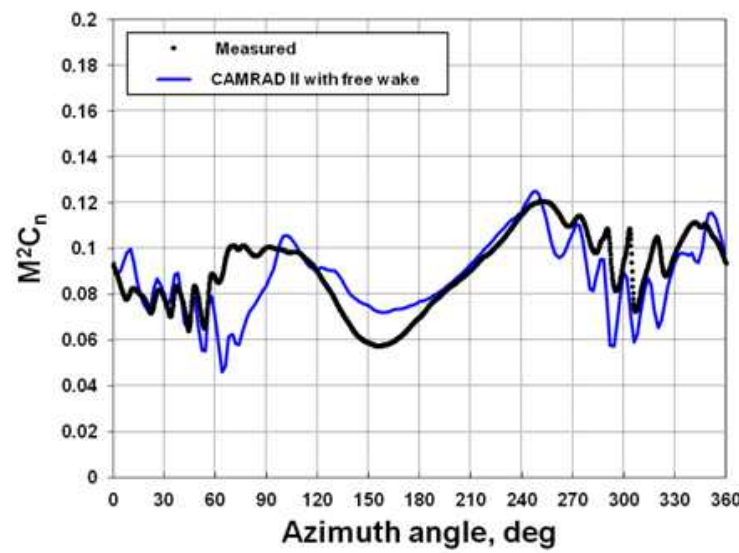

Fig. 1. Comparisons of airloads prediction result about HART ॥ BL case

도의 기울기를 갖는다. Table 2는 HART II 로터 블레이드의 특성 및 제원을 나타낸다.

해석 코드의 검증을 위해 HART II 시험의 $\mathrm{BL}$ 조건에 대해 해석을 수행한 후에 실험값과 비교 하였다. Fig. 1은 CAMRAD II를 이용하여 계산 된 공력하중 결과를 보여준다. 공력하중은 로터 반경의 $87 \%$ 지점에서 측정되었다. 전체적인 해 석은 15 도 간격으로 수행되었지만, 공력 계산에 서는 정밀한 $\mathrm{BVI}$ 해석을 위해서 2도 간격의 추 가적인 계산을 수행하였다. 해석 결과를 보면 전 진면과 후퇴면의 BVI 현상을 비롯한 전반적인 실험결과를 잘 예측하는 것을 볼 수 있다.

Figure 2는 비틀림 모멘트에 대한 해석 결과를 측정값과 비교한 것이다. 비틀림 모멘트는 $33 \%$ 지점에서 측정되었고, 여기에서는 평균값을 제외 한 값을 비교하였다. 해석 결과와 실험값을 비교 해보면 잘 예측하고 있음을 알 수 있다.

Figure 3은 블레이드 익단의 플랩 응답을 나타 낸다. 블레이드 간의 상이성(dissimilarity)으로 인 하여 측정값에 편차가 발생하는 것을 볼 수 있 다. 해석 결과를 살펴보면 $1 / \mathrm{rev}$ 의 블레이드 익

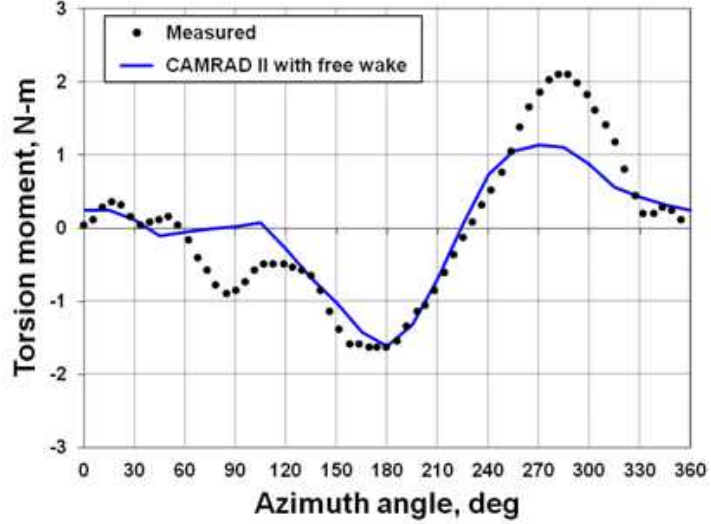

Fig. 2. Comparisons of structural loads prediction result about HART II BL case

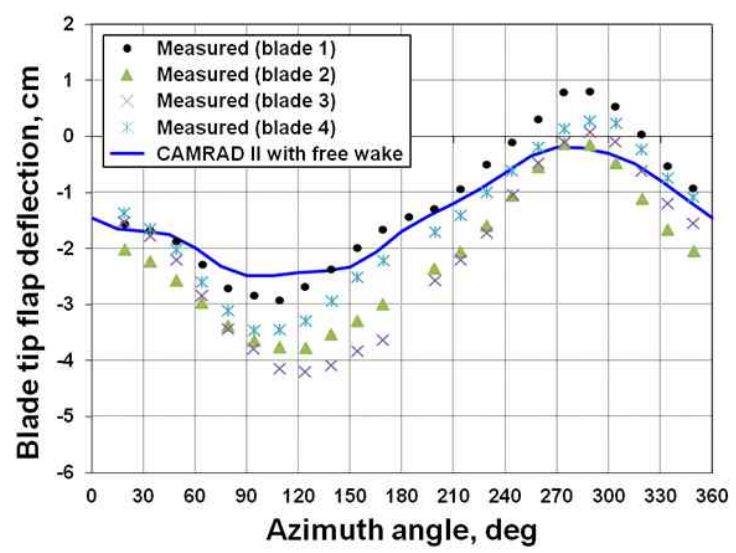

Fig. 3. Comparisons of aeroelastic response prediction result about HART II BL case

단의 플랩응답 거동을 잘 예측하는 것을 볼 수 있다. 이상의 검증과정을 통하여 CAMRAD II를 이용한 모델링이 적절히 이루어졌으며, 진동하중 계산 결과의 신뢰성을 확보하였다고 볼 수 있다.

\section{$2.2 \mathrm{HHC}$ 파라미터 연구}

$\mathrm{HHC}$ 입력조건에 따른 로터 허브 진동하중의 변화를 살펴보기 위해 가진주파수와 진폭, 그리 고 위상각을 변화시켜가며 파라미터 연구를 수행 하였다. $\mathrm{HHC}$ 입력은 회전좌표축에서 블레이드 의 피치 운동으로 표현하였으며 수식으로 나타내 면 다음과 같다.

$$
H(\psi)=A \cos (n \psi-\phi)
$$

여기에서 $A$ 는 진폭, $n$ 은 가진주파수, 그리고 $\phi$ 는 위상각을 나타낸다.

파라미터 해석을 위한 가진주파수와 진폭의 범위는 Splettstoesser 등[13]이 수행한 연구를 참 고하여 선정하였다. 이 연구에서는 $\mathrm{BVI}$ 소음을 
감소시키기 위한 최적의 $\mathrm{HHC}$ 기법을 찾기 위해 BO-105 축소 로터를 이용한 풍동시험을 통하여 가진주파수와 진폭, 그리고 위상각을 변화시켜가 며 소음 및 진동을 측정하였다. 이 연구에서 사 용한 제어입력의 가진주파수는 $3 / \mathrm{rev}, 4 / \mathrm{rev}$ 그 리고 $5 / \mathrm{rev}$ 이고, 진폭은 0.4 도, 0.8 도 그리고 1.2 도이다. 또한 위상각은 약 30 도 간격으로 변화하 였다. 본 연구에서도 이와 동일한 제어입력을 이 용하여 허브 진동하중의 변화를 살펴보았으며, 상대적으로 진동 억제 성능이 우수하다고 판단되 는 구간을 선정하여 이를 다시 5 도 간격으로 세 분화하여 최적의 $\mathrm{HHC}$ 제어입력을 얻도록 구성 하였다.

\section{3 진동 판별 지수 $(\mathrm{VI})$}

$\mathrm{HHC}$ 입력조건에 따른 허브 진동하중을 비교 하기 위하여 VI(Vibration Index)를 정의하는 것 이 필요하다. $\mathrm{VI}$ 는 고정좌표계인 허브축에서의 진동하중을 이용하여 구성하였다. HART II 시험 에서는 식 (2)와 같은 판별식을 이용하여 진동을 비교하였다[11]. 여기에서는 진동하중의 $4 / \mathrm{rev}$ 성 분만을 이용하였으며 이를 수식으로 표현하면 다 음과 같다.

$$
V I^{a}=\sqrt{F_{x, 4 P}^{2}+F_{y, 4 P}^{2}+F_{z, 4 P}^{2}+M_{x, 4 P}^{2}+M_{y, 4 P}^{2}}
$$

여기에서 $F$ 및 $M$ 은 각각 $\mathrm{x}, \mathrm{y}, \mathrm{z}$ 방향에 대한 힘 과 모멘트를 나타낸다.

Figure 4는 HART II 시험의 BL 조건의 허브 진동하중 해석 결과이다. 결과를 살펴보면 허브 진 동하중의 수직방향 힘 $\left(F_{z}\right)$ 의 $8 / \mathrm{rev}$ 성분이 $4 / \mathrm{rev}$ 성분의 크기와 비슷하게 나타나는 것을 볼 수 있 다. 결국 진동하중의 $4 / \mathrm{rev}$ 성분만을 이용하여 만 든 $\mathrm{VI}$ 는 로터의 진동 특성을 제대로 반영하지 못 할 수 있으며, 진동하중의 $4 / \mathrm{rev}$ 과 $8 / \mathrm{rev}$ 을 모두 고려하는 포괄적인 $\mathrm{VI}$ 를 설정할 필요가 있다.

따라서 본 연구에서는 $8 / \mathrm{rev}$ 의 진동하중 성분

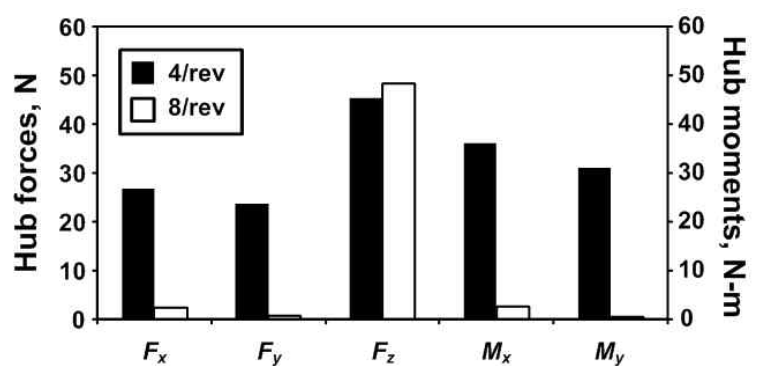

Fig. 4. Comparison of rotor hub vibratory loads for HART II BL case
을 포함하는 새로운 $\mathrm{VI}$ 를 정의하고 기존의 $\mathrm{VI}$ 와 비교하여 $\mathrm{VI}$ 의 정의 방법에 따른 최소 진동하중 을 위한 입력 조건의 변화를 살펴보았다. 우선 기존의 $V I^{a}$ 에 $8 / \mathrm{rev}$ 성분을 추가하여 $V I^{b}$ 를 정 의하고, 진동하중의 힘과 모멘트 성분을 분리시 켜 $V I^{c}$ 를 정의하였다. 이를 수식으로 나타내면 다음과 같다.

$$
\begin{aligned}
V I^{b}= & \sqrt{\begin{array}{l}
F_{x, 4 P}^{2}+F_{x, 8 P}^{2}+F_{y, 4 P}^{2}+F_{y, 8 P}^{2}+F_{z, 4 P}^{2} \\
+F_{z, 8 P}^{2}+M_{x, 4 P}^{2}+M_{x, 8 P}^{2}+M_{y, 4 P}^{2}+M_{y, 8 P}^{2}
\end{array}} \\
V I^{c}= & w_{1} \sqrt{\begin{array}{l}
F_{x, 4 P}^{2}+F_{y, 4 P}^{2}+F_{z, 4 P}^{2} \\
+F_{x, 8 P}^{2}+F_{y, 8 P}^{2}+F_{z, 8 P}^{2}
\end{array}} \\
& +w_{2} \sqrt{M_{x, 4 P}^{2}+M_{y, 4 P}^{2}+M_{x, 8 P}^{2}+M_{y, 8 P}^{2}}
\end{aligned}
$$

여기에서 $w_{1}$ 과 $w_{2}$ 는 가중계수를 나타내고, 본 연구에서는 각각 1 로 설정하였다.

파라미터 연구를 통하여 구한 허브 진동하중 이 $\mathrm{VI}$ 를 정의하는 방법에 따라 어떻게 달라지는 지를 확인할 필요가 있다. 다음 절에서는 $\mathrm{VI}$ 를 정의하는 방법에 따라서 진동의 특성이 어떻게 달라지는지 $3 / \mathrm{rev} \mathrm{HHC}$ 입력 조건을 이용하여 분석하였다.

\section{4 해석 결과}

\subsubsection{3/rev HHC input}

$3 / \mathrm{rev}$ 의 가진주파수를 갖는 $\mathrm{HHC}$ 입력을 가하 였을 경우의 허브 진동하중의 감소량을 Fig. 5에 보였다. 계산된 허브 진동하중은 기준조건(BL)에 서 구한 진동하중과 비교하여 그 변화량을 백분 율로 나타내었다. 결과를 살펴보면 $\mathrm{VI}$ 를 구성하 는 방법에 따라 허브 진동하중의 변화량의 차이 는 크지 않으나 최소 진동하중을 달성하는 제어 입력에서는 차이를 보여주고 있다. 진동하중의 $4 / \mathrm{rev}$ 성분만을 이용한 $V I^{a}$ 를 이용한 경우에는 0.4 도의 진폭과 330 도의 위상각을 갖는 경우에서 기준조건 대비 약 $37 \%$ 의 진동하중 감소효과를 나타내는 반면에 진동하중의 $4 / \mathrm{rev}$ 과 $8 / \mathrm{rev}$ 을 모두 고려한 $V I^{b}$ 와 $V I^{c}$ 를 이용한 경우에서는 0.8 도의 진폭과 0 도의 위상각을 갖는 경우에서 각각, 기준조건 대비 약 $38 \%$ 와 $39 \%$ 의 진동하중 감소효과를 나타냈다. 하지만 진동하중의 힘과 모멘트 성분을 분리시킨 $V I^{c}$ 와 분리시키지 않은 $V I^{b}$ 의 경향성은 거의 동일한 것을 볼 수 있다. 가중계수를 고려하지 않고 진동하중의 힘과 모멘 트 성분만을 분리시키는 경우에서는 최소 진동하 


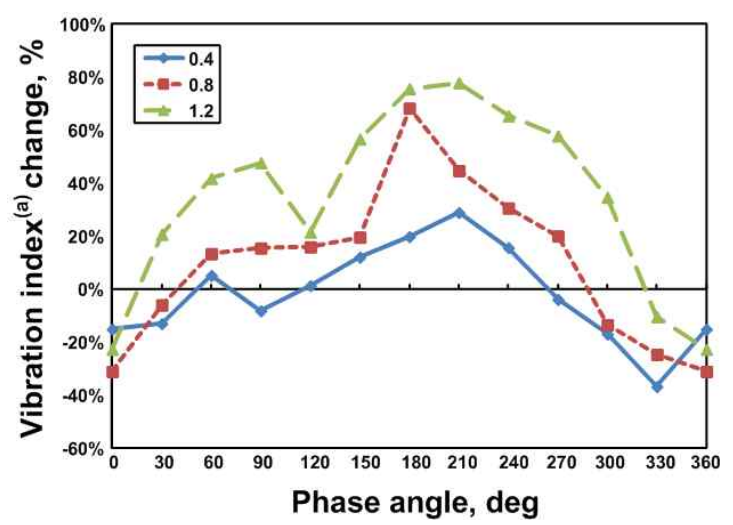

(a) $V I^{a}$

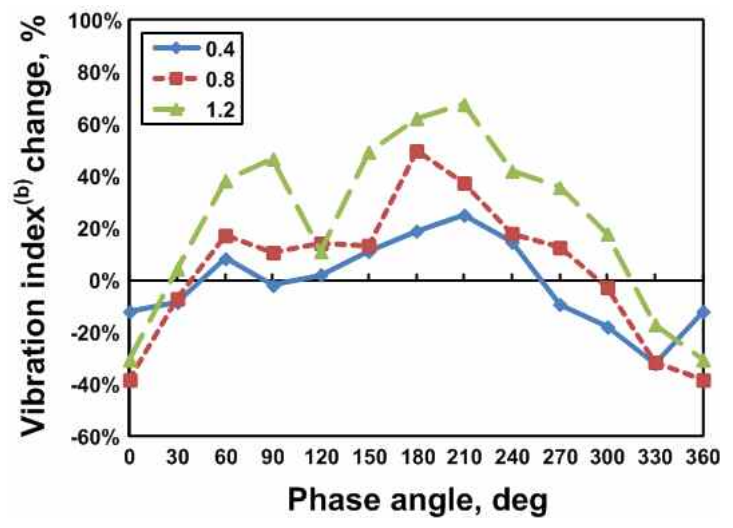

(b) $V I^{b}$

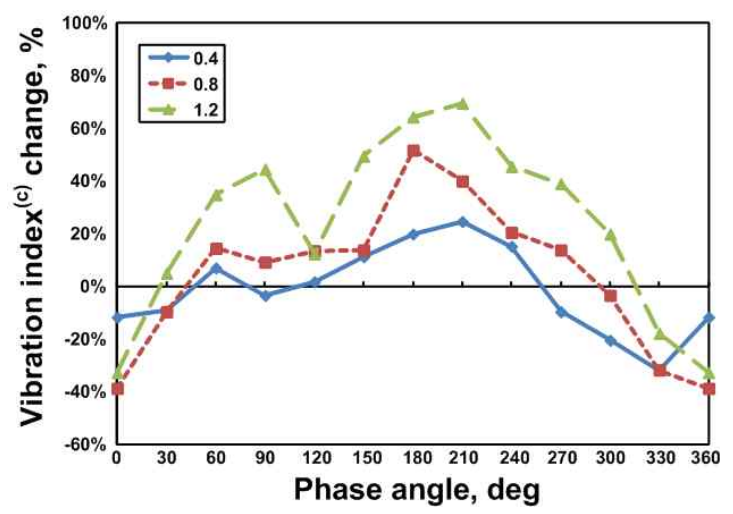

(c) $V I^{c}$

Fig. 5. Vibration index change due to $3 /$ rev $\mathrm{HHC}$ input

중을 달성하는 제어입력에 큰 영향을 주지 않는 것을 볼 수 있다. 이후의 $4 / \mathrm{rev}$ 과 $5 / \mathrm{rev}$ 의 가진 주파수로 제어입력을 가하는 경우에서는 $V I^{c}$ 를 기준으로 허브 진동하중의 변화량을 비교하고 최 소 진동하중을 위한 제어입력을 탐색하였다.

HART II 시험의 MV 조건은 Table 1에서 나 타낸 바와 같이 0.79 도의 진폭과 180 도의 위상각 의 제어입력을 갖는다. 동일한 제어입력을 이용 하였을 경우의 진동하중을 보면 오히려 진동하중
이 증가하는 것을 볼 수 있다. 이러한 비교결과 만으로 HART II 시험에서의 $\mathrm{MV}$ 조건이 실제 최소 진동을 달성하는 조건이 아니었음을 단정하 기에는 다소 어려움이 있다. HART II 시험에서 측정된 진동하중과 해석을 통하여 구한 허브 진 동하중을 직접적으로 비교하기에는 HART II 시 험의 진동하중 측정 방법이나 데이터 후처리 방 법 등이 잘 알려져 있지 않은 측면이 있기 때문 이다. 또한 실제 시험과 해석 모델의 차이로 인 한 가능성도 배제하기 어려운 실정이다. 해석 모 델은 단독 로터 시스템만 고려하여 허브 진동하 중을 계산하지만, 실제 시험에서는 로터를 구동 하기 위한 서브시스템의 고유진동 특성이 로터와 상호 연계되어 허브 진동하중에 영향을 미치기 때문이다. 이러한 차이를 줄이기 위해서는 로터 와 동체를 상호 연계하는 해석이 필요하고, 추후 에 이 부분에 대한 연구를 수행할 예정이다.

$\mathrm{HHC}$ 입력에 따른 로터의 성능 변화를 요구 동력(required power) 관점에서 비교하였다. Fig. 6은 $\mathrm{HHC}$ 입력의 크기에 따른 로터 파워의 변화 를 나타낸다. Fig. 5와 6을 비교해서 살펴보면 위 상각에 따른 로터 파워의 변화가 허브 진동하중 과 반대 방향의 경향성을 나타내는 것을 인식할 수 있다. 즉, 허브 진동하중을 최소화시키는 위상 각에서는 오히려 로터의 파워가 증가함으로 성능 이 저하되고, 로터의 파워가 최소화하는 위상각 에서는 허브 진동하중이 증가하는 경향을 보인 다. 로터 파워가 가장 많이 감소하는 제어입력은 0.4 도의 진폭과 150 도의 위상각을 갖는 입력이다. 이 제어입력에서 약 $3.7 \%$ 의 파워가 감소하는 것 을 볼 수 있다. 하지만 로터 파워를 최소화 시키 는 제어입력은 진폭의 변화에 큰 영향을 받지 않 음을 알 수 있다. 결국 진폭의 크기에 관계없이

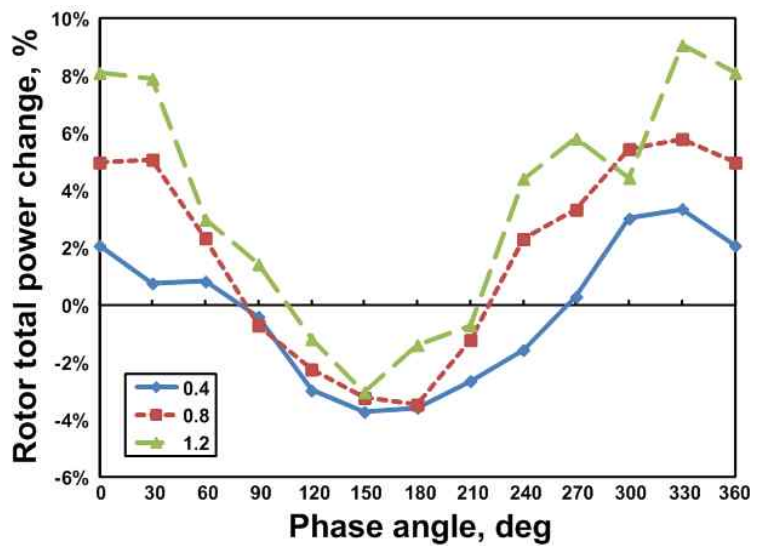

Fig. 6. Roto power change due to $3 /$ rev $\mathrm{HHC}$ input 
최대 약 $3 \%$ 정도의 로터 파워를 감소시키는 위 상각이 존재한다.

\subsubsection{4/rev HHC input}

Figure 7 은 $4 / \mathrm{rev}$ 가진주파수를 갖는 서로 다 른 제어입력에 대한 허브 진동하중의 파라미터 해 석 결과이다. 결과를 보면 0.4 도의 진폭을 갖는 경 우를 제외하고 거의 모든 영역에서 진동하중이 증 가하는 것을 볼 수 있다. 진동의 증가량은 진폭이 커질수록 이에 비례하여 증가하고 있다. 최대의 진동하중 감소는 0.4 도의 진폭과 30 도의 위상각을 갖는 제어입력에서 얻을 수 있으며, 기준조건 대 비 약 $20 \%$ 감소된 허브 진동하중을 나타낸다.

Figure 8 은 $4 / \mathrm{rev}$ 제어입력의 기준대비 로터 파워의 변화량을 보인 것이다. 로터 파워의 변화 량은 진동하중의 변화량과 유사하게 0.4 도의 진 폭 조건을 제외하고 대부분 증가하는 것을 볼 수 있다. 가장 큰 로터 파워의 감소는 0.4 도의 진폭 과 0 도의 위상각을 갖는 제어입력 조건에서 발생 하며 기준대비 약 $1.9 \%$ 감소하고 있다.

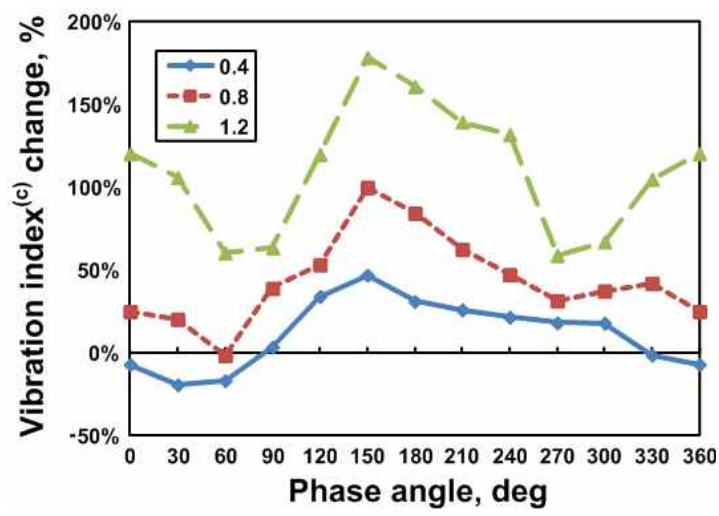

Fig. 7. Vibration index change due to 4/rev HHC input

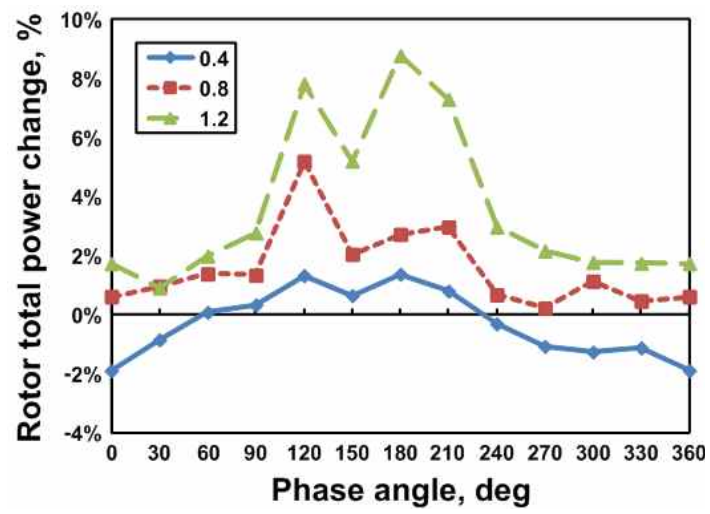

Fig. 8. Rotor power change due to 4/rev HHC input

\subsubsection{5/rev HHC input}

Figure 9 는 $5 / \mathrm{rev}$ 의 가진주파수를 갖는 제어입 력에 대한 진동하중의 변화량을 나타낸다. 앞에 서 살펴본 $4 / \mathrm{rev}$ 의 가진주파수를 갖는 제어입력 조건의 결과와 유사하게 대부분의 입력 조건에서 진동하중이 증가하는 것을 볼 수 있다. 하지만 증가량의 크기는 $4 / \mathrm{rev}$ 의 제어입력 조건보다는 작게 나타난다. $4 / \mathrm{rev}$ 의 제어입력에서는 최대 약 $180 \%$ 까지 진동이 증가하는 것이 비해 $5 / \mathrm{rev}$ 의 제어입력에서는 최대 약 $140 \%$ 까지 진동이 증가 하는 것을 볼 수 있다. 최대의 진동하중 감소효 과는 0.4 도의 진폭과 30 도의 위상각을 갖는 경우 에서 나타나고, 기준 조건 대비 약 $27 \%$ 감소 효 과를 얻을 수 있다.

Figure 10 은 $5 / \mathrm{rev}$ 의 제어입력을 가하는 경우 의 로터 파워의 변화량을 나타낸다. Fig.을 살펴 보면 약 240 도 부근의 위상각에서 모든 진폭 조 건에 대하여 가장 큰 로터 파워 감소효과를 보여 준다. 최대의 로터 파워 감소량을 보여주는 조건 은 0.4 도의 진폭과 210 도의 위상각을 갖는 조건

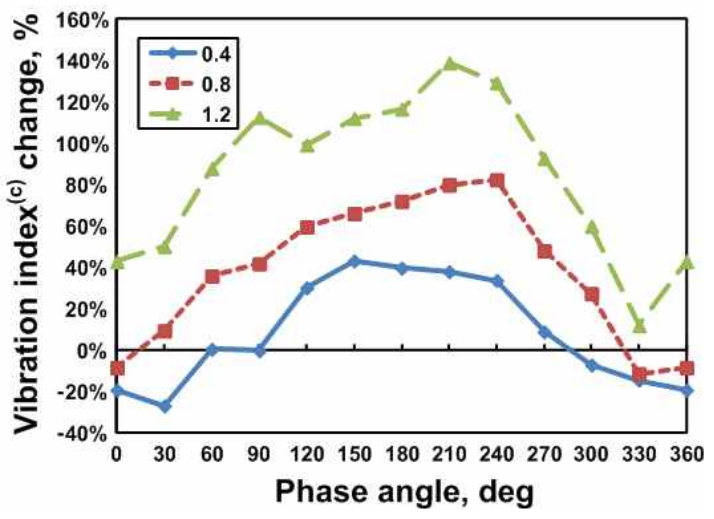

Fig. 9. Vibration index change due to 5/rev HHC input

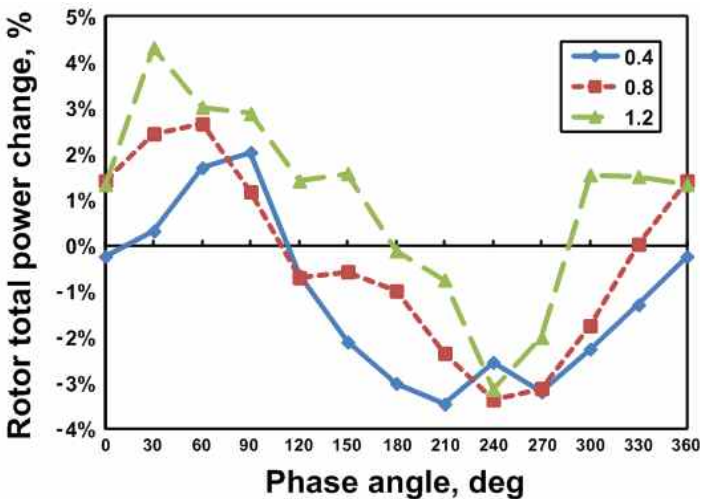

Fig. 10. Rotor power change due to 5/rev HHC input 
이고, 이 입력 조건에서 약 $3.5 \%$ 의 로터 파워를 감소효과가 있음을 알 수 있다.

\subsection{4 최적 제어입력 조건}

앞에서 살펴본 제어입력에 따른 허브 진동하 중과 로터 파워의 변화를 종합적으로 분석하여 허브 진동하중을 최대로 감소시키기 위한 제어입 력과 허브 진동하중과 로터 파워를 동시에 감소 시키는 제어입력을 선정하였다.

허브 진동하중과 로터 파워를 동시에 감소시 키는 최적 제어입력은 $5 / \mathrm{rev}$ 의 가진주파수에서 찾을 수 있다. 0.4 도의 진폭과 330 도의 위상각을 갖는 경우에 허브 진동하중은 약 $21.5 \%$ 감소시 키면서 동시에 로터 파워를 약 $1.3 \%$ 감소시키는 것을 확인하였다.

허브 진동하중만을 최대로 감소시키는 제어입 력은 $3 / \mathrm{rev}$ 의 가진주파수를 갖는 입력조건이다. $4 / \mathrm{rev}$ 과 $5 / \mathrm{rev}$ 의 가진주파수를 갖는 제어입력에 서는 0.4 도의 진폭을 갖는 경우를 제외하고 진동 하중이 모두 증가하는 경향을 나타내었고, 진동 의 크기가 기준조건의 2 배를 넘는 경우도 가능하 였다. 하지만 $3 / \mathrm{rev}$ 의 가진주파수를 갖는 제어입 력에서는 기준조건의 2 배를 넘어가는 진동하중은 발생하지 않는 것을 확인하였다.

$3 / \mathrm{rev}$ 의 가진주파수를 갖는 제어입력에서 허 브 진동하중을 최대로 감소시키는 입력조건은 0.8 도의 진폭과 0 도의 위상각이다. 하지만 이는 30 도 간격의 위상각을 이용한 해석 결과이고, 실 제 최소 진동조건은 330 도와 30 도 사이에 존재할 것이다. 따라서 이 구간을 다 5 도 간격으로 잘게 나누어 해석하여, 최소 진동조건을 구하였다.

Figure 11은 위상각을 5도 간격으로 구분하여 얻은 허브 진동 해석 결과이다. Fig.을 살펴보면 최소 진동조건은 0.8 도의 진폭과 350 도의 위상각 에서 발생하는 것을 확인할 수 있다. 이 제어입 력 조건에서 허브 진동하중은 기준조건대비 약 $45 \%$ 감소된 진동수준을 나타낸다.

\section{III. 결 론}

본 연구에서는 통합 공탄성 해석 프로그램에 $\mathrm{HHC}$ 기법을 적용하여 저속하강 비행조건에서 로터의 허브 진동하중 감소효과를 살펴보고, 최 대의 진동하중 억제를 위한 제어입력 조건을 구 하였다. 본 연구를 통하여 다음과 같은 결론을 얻었다.

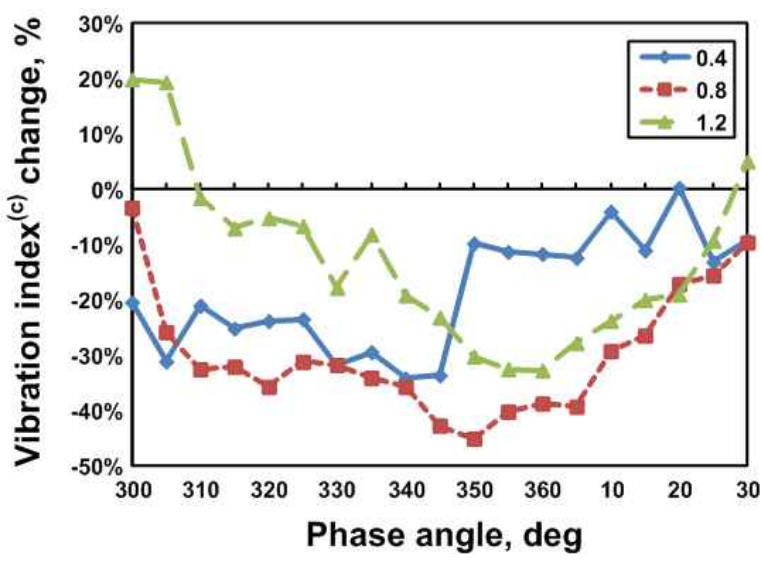

Fig. 11. Effect of amplitude sweep of vibratory hub loads change due to $3 /$ rev HHC input

(1) 진동하중의 변화를 정량화하기 위한 $\mathrm{VI}$ 를 구성하기 위하여 기존의 $4 / \mathrm{rev}$ 허브하중 이외에 도 $8 / \mathrm{rev}$ 성분을 추가로 고려하는 새로운 $\mathrm{VI}$ 를 구성하였다. $4 / \mathrm{rev}$ 성분만을 이용한 $\mathrm{VI}$ 에서는 0.4 도의 진폭과 330 도의 위상각에서 최소 진동 조건을 찾을 수 있지만 $8 / \mathrm{rev}$ 성분을 포함한 $\mathrm{VI}$ 에서는 0.8 도의 진폭과 0 도의 위상각에서 최소 진동 조건을 찾을 수 있었다.

(2) 주파수, 진폭 및 위상각 변동해석의 결과 $3 / \mathrm{rev}$ 의 가진주파수를 갖는 제어입력의 경우에 가장 큰 허브 진동하중 감소 효과를 얻었으며, 0.8 도의 진폭과 350 도의 위상각에서 약 $45 \%$ 감 소된 진동하중을 얻었다. 반면에 $4 / \mathrm{rev}$ 의 가진주 파수를 갖는 경우는 최대 약 $20 \%$ 의 감소효과를 갖고, $5 / \mathrm{rev}$ 의 가진주파수를 갖는 경우는 최대 약 $27 \%$ 의 감소효과를 갖는다. 해석에서 얻은 $\mathrm{MV}$ 조건은 HART II 시험의 MV 조건과 상당히 다른 결과를 나타내며, 이 조건에서는 오히려 진 동이 증가하는 경향을 보였다.

(3) $\mathrm{HHC}$ 기법을 적용하여 로터 파워를 감소 시킬 수 있음을 확인하였다. 최대의 로터 파워의 감소 효과는 $3 / \mathrm{rev}$ 가진주파수의 0.4 도 진폭과 150 도 위상각에서 볼 수 있으며, 최대 $3.7 \%$ 감소 하는 것을 보였다.

(4) 로터 파워가 감소하는 제어입력에서는 대 체로 진동하중이 증가하는 경향을 보였지만, 로 터의 진동과 파워를 동시에 감소시키는 입력 조 건을 찾을 수 있었다. $5 / \mathrm{rev}$ 의 가진주파수를 갖 고 0.4 도의 진폭과 330 도의 위상각을 갖는 입력 조건에서 진동하중은 기준대비 약 $21.5 \%$ 감소하 고 동시에 로터 파워도 약 $1.3 \%$ 감소하는 것을 보였다. 


\section{후 기}

이 논문은 2011학년도 건국대학교의 연구년 교원지원에 의하여 연구되었음

\section{References}

1) Amer, K. B., and Neff, J. R., Vertical Plane Pendulum Absorbers for Minimizing Helicopter Vibratory Loads," Journal of the American Helicopter Society, Vol. 19, No. 4, 1974, pp.44 48.

2) Taylor, R. B., "Helicopter Vibration Reduction by Rotor Blade Modal Shaping," 38th AHS Annual Forum, Anaheim, 1982, pp.99 101.

3) Welsh, W. A., von Hardenberg, P. C., and Staple, A. E., "Test and Evaluation of Fuselage Vibration Utilizing Active Control of Structural Response(ASCR) Optimized to ADS-27," 46th AHS Annual Forum, Washington DC, 1990, pp.21 37.

4) Nguyen, K., and Chopra, I., "Application of Higher Harmonic Control to Rotors Operating at High Speed and Thrust," Journal of the American Helicopter Society, Vol. 35, No. 3, 1990, pp.78 89.

5) Jacklin, S. A., Habor, A., de Simone, G., Norman, T. R., Kitaplioglu, C., and Shinoda, P., "Full-Scale Wind Tunnel Test of an Individual Blade Control System for a UH-60 Helicopter," 58th AHS Annual Forum, Montreal, 2002, pp.1103 1114.

6) Ravichandran, K., Ananthan, S., Chopra, I. and Hein, B., "Active Rotor Controls for
Vibration Reduction and Performance Enhancement," AHS Specialists' Conference on Aeromechanics, San Fancisco, CA, 2010.

7) Matthew, L. W., Paul, H., M., William, T. Y., Jr., Chester, W., L., Carlos, E. S. C., and Shin, S. J., "Vibratory Loads Reduction Testing of the NASA/ARMY/MIT Active Twist Rotor," 57th AHS Annual Forum, Washington DC, 2001.

8) Payne, P. R., "Higher Harmonic Control," Aircraft Engineering, Vol. 30, 1958, pp.222 226.

9) Kessler, Ch., "Active Rotor Control for Helicopters: Motivation and Survey on Higher Harmonic Control," 36th European Rotorcraft Forum, 2010, Paper 045-I.

10) Lim, J. W., Tung, C., Yu, Y. H., "Prediction of Blade-Vortex Interaction Airloads with Higher-Harmonic Pitch Controls using the 2GCHAS Comprehensive Code," Journal of Pressure Vessel Technology, Vol. 123, 2001, pp.469 474.

11) van der Wall, B. G., "2nd HHC Aeroacoustic Rotor Test(HART II) - Part I: Test Documentation - Institute Report IB 111-2003/31," German Aerospace Center (DLR), Braunschweig, Germany, 2003.

12) Johnson, W. "CAMRAD II, Comprehensive Analytical Model of Rotorcraft Aerodynamics and Dynamics," Palo Alto, CA, Johnson Aeronautics, 1992.

13) Splettstoesser, W. R., Schultz, K. J., Kube, R., Brooks, T. F., Booth, E. R., Niesl, G., Streby, O., "A Higher Harmonic Control Test in the DNW to Reduce Impulsive BVI Noise," Journal of the American Helicopter Society, Vol. 39, No. 4, 1994, pp.3 13. 